\title{
Effects of syllable duration on stop-glide identification in syllable-initial and syllable-final position by humans and monkeys
}

\author{
JOAN M. SINNOTT, CHARLES H. BROWN, and MELISSA A. BORNEMAN \\ University of South Alabama, Mobile, Alabama
}

\begin{abstract}
Humans and monkeys were compared in their identification of phoneme boundaries along synthetic stop-glide continua in syllable-initial/ba/-/wa/or syllable-final /bab/-/baw/ contrasts differing in overall syllable duration. For both contrasts, humans were first tested with a conventional written identification procedure. Here, similar phoneme boundaries emerged and shifted with increases in syllable duration toward longer transitions, as has previously been reported in the literature for syllable-initial data (Miller \& Liberman, 1979). Humans and monkeys were then tested on these contrasts, using a go/no-go identification procedure specifically designed for monkeys. Here also, stop-glide boundaries emerged and shifted with increased syllable duration for both species, although monkey "boundaries" were at longer durations than humans' in syllable-final position. The results indicate that there are both gross similarities and subtle differences between humans and monkeys with regard to the stop-glide context effect. The results are discussed in relation to the hypothesis that general mammalian auditory mechanisms are responsible for this effect.
\end{abstract}

For the past 20 years, researchers have been examining animal perception of human speech sounds in an effort to determine whether aspects of human perception are species specific (i.e., unique to humans) or species general (i.e., inherited from ancestral primate, mammalian, or vertebrate ancestors).

Some data indicate similarities with human perception. For example, there is now a large body of data on animal phoneme boundaries. Some of these results point to animal boundaries that are similar to those of Englishspeaking humans (Dooling, Best, \& Brown, 1995; Dooling, Okanoya, \& Brown, 1989; Kuhl, 1981; Kuhl \& Miller, 1978; Kuhl \& Padden, 1982, 1983), but there are some exceptions to this rule (Dooling et al., 1989 [velar voice onset time boundaries]; Sinnott \& Brown, 1997; Waters \& Wilson, 1976). Additional data have shown that animals have some degree of perceptual constancy for vowels (Burdick \& Miller, 1975; Dooling \& Brown, 1990; Kojima \& Kiritani, 1989) and can construct phonetic categories for the feature of voice onset time (Kuhl \& Miller, 1978) and place of articulation (Kluender, Diehl, \& Killeen, 1987). Finally, animals appear to be sensitive to trading relations

This research was supported by NIH RCDA Awards K04 DC00042 and R01 DC00541 to J.M.S. Portions of this research were based on a master's thesis by M.A.B. in the Department of Speech Pathology and Audiology at the University of South Alabama. We thank Mitch Barnett, Regina Kressley, Irma Lopez, Waseem Malik, Jane Moore, Kelly Mosteller, Becky Roush, and Trina Williamson for participating as human subjects and for testing animals. We thank Robert Remez, Peter Bailey, and two anonymous reviewers for comments on this manuscript. Correspondence should be addressed to J. M. Sinnott, Department of Psychology, University of South Alabama, Mobile, AL 36688 (e-mail: jsinnott@jaguarl.usouthal.edu). in speech sounds, by which a listener recognizes that two different acoustic cues are perceptually equivalent and will trade with each other in signaling the same phonetic element (Kluender, 1991; Kluender \& Lotto, 1994; Sinnott \& Brown, 1997).

On the other hand, some studies point to differences between animal and human perception of speech. Studies of basic differential sensitivity to the cues underlying speech sounds typically reveal that monkeys have difference limens (DLs) that are about twice those of humans (Sinnott, 1994; but see Sinnott \& Brown, 1997, for a notable exception). Also, Kuhl (1991) has reported that monkeys do not exhibit the human perceptual magnet effect, whereby a listener exhibits greater generalization, and hence poorer discrimination, to variation around good prototypes of vowel categories. Finally, multidimensional scaling experiments using vowels have shown that chimpanzees and monkeys appear to be less sensitive than humans to the second formant, which for humans is phonetically the most important (Kojima \& Kiritani, 1989; Sinnott, Brown, Malik, \& Kressley, 1997).

The purpose of the present experiment was to compare humans and monkeys in terms of a well-known context effect that occurs in speech: the stop-glide phoneme boundary shift effect (Miller \& Liberman, 1979). It is well known that the duration of the initial formant transition is the principal cue that distinguishes the stop consonant $/ \mathrm{b} /$ from the glide / $\mathrm{w} /$. However, Miller and Liberman discovered an additional variable: In identification tests conducted with human adults, phoneme boundaries shifted to longer transition durations as syllable duration increased. For example, a syllable duration of $80 \mathrm{msec}$ resulted in a boundary at about $32 \mathrm{msec}$, 
but a syllable duration of $296 \mathrm{msec}$ resulted in a boundary at about $48 \mathrm{msec}$.

Although these results were initially considered as evidence reflecting a human listener's compensation for speaking rate (Miller \& Liberman, 1979), it is now generally believed that the effect is based on some sort of general psychoacoustic temporal processing mechanism. Evidence supporting the latter view comes from adult human listeners, who perceive similar boundary shifts in analagous nonspeech stimuli (Diehl \& Walsh, 1989; Pisoni, Carrell, \& Gans, 1983), and from prelinguistic human infants, who show the effect for both speech stimuli (Eimas \& Miller, 1980) and nonspeech stimuli in sucking-habituation discrimination paradigms (Jusczyk, Pisoni, Reed, Fernald, \& Myers, 1983).

One important reason for testing animal perception of such effects, despite the data on human nonspeech, is to rule out the possibility that humans may be simply transferring their speech perception strategies to nonspeech stimuli. Therefore, two preliminary studies in which animals have been reported to exhibit the phoneme boundary shift effect with $/ \mathrm{b} /-/ \mathrm{w} /$ stimuli using discrimination procedures (Dent, Powell, Pierce, \& Dooling, 1995; Stevens, Kuhl, \& Padden, 1988) are of interest for further exploration.

In the present study, we directly compared the locations of stop-glide phoneme boundaries and the shift effect for humans with those for monkeys, using an identification procedure specifically designed for monkeys. Since, for the most part, identification procedures have been used to investigate the boundary shift effect in humans, the present data thus obtained could be compared more easily with the published human data. An additional goal of the study was to examine the stop-glide context effect in syllable-final/bab/-/baw/position, which has not yet been examined in humans.

\section{GENERAL METHOD}

\section{Subjects}

The subjects were 6 female humans (the author J.M.S., B.S.R., I.C.L., J.E.M., R.A.K., and T.L.A.), 3 male humans (D.M.B., K.W.M., and W.A.S.), and four 6-year-old male Japanese macaque monkeys (Macaca fuscata; Andy, Dart, Harry, and Port). All of the human subjects except J.M.S. were in their mid-twenties and were naive as to the purpose of the experiment at the time of testing. J.M.S., J.E.M., K.W.M., and the 4 monkeys had previously participated in other psychoacoustic and speech discrimination experiments.

All of the humans were native speakers of American English except for I.C.L. and W.A.S., who were native speakers of Spanish and Hindi, respectively. Both had been in the U.S. speaking English for about 10 years and spoke with accents. Although Spanish has a $\mathrm{b} /$ sound, it has no $/ \mathrm{w} /$ sound, while Hindi has $\mathrm{a} / \mathrm{b} /-/ \mathrm{w} /$ contrast similar to that in English. We included these 2 subjects because they regularly worked in our lab and because most current theorizing points to general auditory mechanisms as a basis of the stop-glide context effect, whereby non-English speakers would also be expected to show the effect.

\section{Apparatus}

The humans and monkeys were tested in a double-walled IAC booth $(1.8 \times 1.9 \times 2.0 \mathrm{~m})$ padded with sound-insulating acoustic foam (Sonex). The subjects responded on a contact-sensitive metal disk mounted over a cuelight embedded in Plexiglas. The stimulus system included a 12-bit D/A converter (Data Translation) and lowpass filter (Frequency Devices) set at $4800 \mathrm{~Hz}(24 \mathrm{~dB}$ per octave roll-off), programmable attenuators (Data Translation), an amplifier (NAD), and a loudspeaker (Polk 10). This system had a flat $( \pm 4 \mathrm{~dB}$ ) frequency response from 100 to $4800 \mathrm{~Hz}$. The monkeys sat in primate chairs and received $190-\mathrm{mg}$ banana-flavored pellets as rewards from an automatic feeder. All experimental contingencies were controlled by a Compaq computer.

\section{Stimuli}

All the stimuli were generated on the Canadian Speech Research Environment (University of Western Ontario). The stimuli were synthesized and presented at a $10-\mathrm{kHz}$ sampling rate using a $5-\mathrm{msec}$ synthesis frame rate. The stimuli contained the steady-state vowel $/ \mathrm{a} /$ with $F 1=700, F 2=1200$, and $F 3=2600 \mathrm{~Hz}$. $F 0$ fell linearly over the duration of the syllables from 125 to $80 \mathrm{~Hz}$. F4 and $F 5$ remained fixed at 3300 and $3700 \mathrm{~Hz}$. The bandwidths for $F 1-F 5$ were $90,90,130,400$, and $500 \mathrm{~Hz}$, respectively. The amplitude of voicing, as synthesized, began at $55 \mathrm{~dB}$ and decreased from this value to 0 over the last $20 \mathrm{msec}$ of each syllable. In addition, the stimuli were gated externally with a single $10-\mathrm{msec}$ rise time, since it has been shown that amplitude changes have a very small effect in stop-glide identification relative to transition durations (Nittrouer \& Studdert-Kennedy, 1986).

Syllable-initial position. A short $(120-\mathrm{msec})$ and a long (320$\mathrm{msec}$ ) / ba/-/wa/ continuum were constructed, each consisting of 10 stimuli that varied according to the duration of the initial formant transition, which ranged from 10 to $100 \mathrm{msec}$ in $10-\mathrm{msec}$ steps. The duration of the steady-state vowel was manipulated so that the overall syllable duration remained constant for each series. For example, the 1 st short stimulus had a 10 -msec transition combined with a $110-\mathrm{msec}$ vowel, and the 10th stimulus had a $100-\mathrm{msec}$ transition combined with a $20-\mathrm{msec}$ vowel. The $1 \mathrm{st}$ long stimulus had a 10 -msec transition combined with a $310-\mathrm{msec}$ vowel, and the 10 th stimulus had a 100 -msec transition combined with a 220 -msec vowel. The frequency trajectories of the formant transitions were as follows: $F 1$ moved from 400 to $700 \mathrm{~Hz}$ over the initial transition and remained at $700 \mathrm{~Hz}$ during the vowel. Over these same time periods, $F 2$ moved from 1000 to $1200 \mathrm{~Hz}$, and $F 3$ moved from 2400 to $2600 \mathrm{~Hz}$. Schematized spectrographic patterns of these syllableinitial stimuli are shown in Figures $1 \mathrm{a}-1 \mathrm{~b}$.

Syllable-final position. Short ( $150-\mathrm{msec})$ and long $(350 \mathrm{msec})$ / bab /-/ baw / continua were constructed as follows: For both continua, all syllables contained a $30-\mathrm{msec}$ initial transition appropriate for / b /, a portion of steady-state vowel, and a final variable-duration transition appropriate for/ab/or/aw/. The series for each continuum was created by varying the duration of the final formant transition from 10 to $100 \mathrm{msec}$ in 10 -msec steps, producing 10 stimuli per series. As the duration of the final transition increased, the steadystate vowel decreased by the identical amount, so that the overall duration of each series remained constant. Thus, the 1 st short stimulus had a fixed $30-\mathrm{msec}$ initial transition, a $110-\mathrm{msec}$ vowel, and a $10-\mathrm{msec}$ final transition; the 10 th had a $30-\mathrm{msec}$ initial transition. a 20 -msec vowel, and a final 100 -msec transition. The 1st long stimulus had a $30-\mathrm{msec}$ initial transition, a $310-\mathrm{msec}$ vowel, and a final 10 -msec transition; the 10th had a 30 - $\mathrm{msec}$ initial transition, a 220 msec vowel, and a final 100 -msec transition. The frequency ranges of the formant transitions were identical to those for the syllableinitial series. Schematized patterns of the first and last stimuli in the syllable-final series are shown in Figures $1 \mathrm{c}-1 \mathrm{~d}$.

\section{Experimental Procedures}

Written identification. The purpose of this procedure was to obtain stop-glide identification data from human subjects, using a conventional written identification procedure. Each subject sat inside the test booth, listened to stimuli from the continua, and wrote 
(a) SHORT BA-WA CONTINUUM

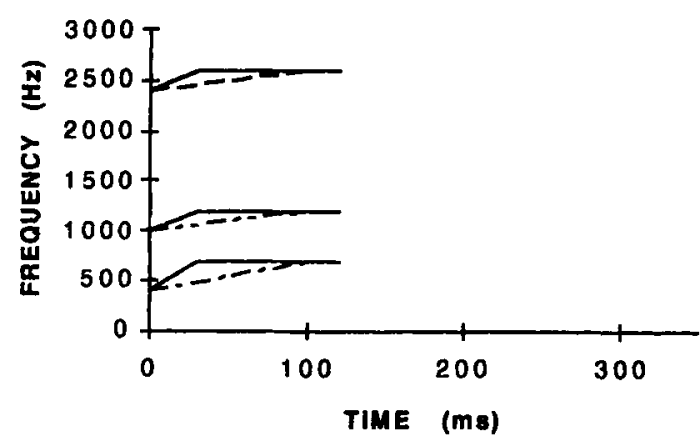

(c) SHOAT BAB-BAW CONTINUUM

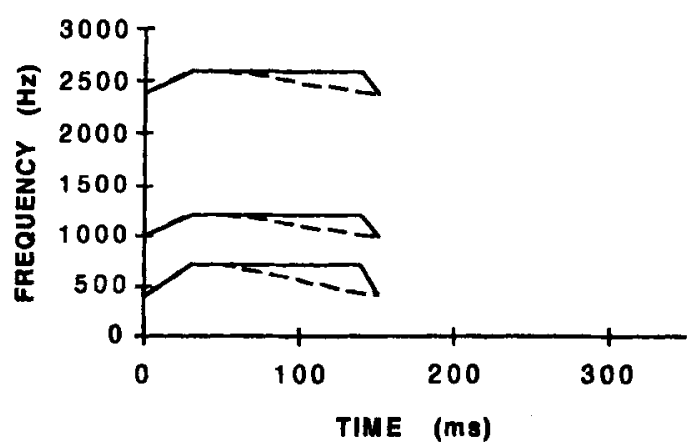

(b) LONG BA-WA CONTINUUM

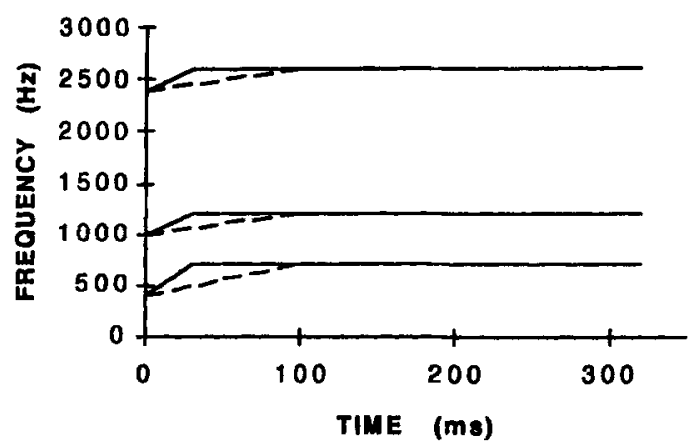

(d) LONG DAB-BAW CONTINUUM

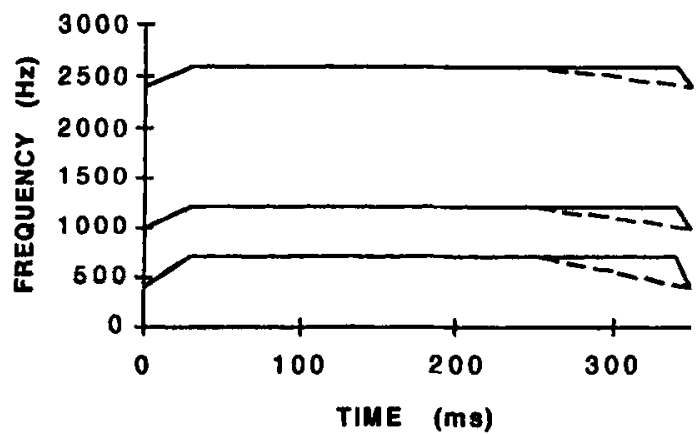

Figure 1. Schematized spectrographic patterns of the stop-glide stimuli. (a) Short / ba /-/wa / continuum of 120 -msec duration. (b) Long / ba / / wa / continuum of 320-msec duration. Solid lines show the transitions for initial 30-msec/ba/; dotted lines show the transitions for initial 100-msec/wa/. (c) Short/bab/-/baw/ continuum of 150-msec duration. (d) Long / bab/-/baw/ continuum of 350-msec duration. Solid lines show the transitions for final 30-msec/bab/; dotted lines show the transitions for final $100-\mathrm{msec} / \mathrm{bow} /$.

down on an answer sheet whether the stimulus sounded more like $/ \mathrm{a} /, / \mathrm{ba} /$, or $/ \mathrm{wa} /$ for the syllable-initial stimuli, or $/ \mathrm{ba} /, / \mathrm{bab} /$, or/baw/for the syllable final stimuli. The syllable-initial and final conditions were tested separately: All subjects were tested first in the syllable-initial condition.

Each subject worked at her/his own pace. A trial was begun by contacting the response disk, at which time a randomly chosen stimulus started to repeat at a rate of 1 per sec at $60 \mathrm{~dB}$ SPL (A) until the subject released the disk. The stimuli were presented in daily sessions that alternated between the short and the long series, with a total of five sessions occurring for each series. Each session consisted of 80 trials representing 8 identifications of each of the 10 stimuli, so the final data were based on 40 identifications per stimulus.

Go/no-go identification. The go/no-go identification procedure was based on one previously developed by Kuhl and Miller (1978). All subjects were tested first in the syllable-initial condition. A trial sequence began with the flashing cuelight. When the subject contacted the disk, the light steadied, and after a variable silent interval of 2-4 sec, a single stimulus from the continuum was presented twice and pulsed at a rate of $1 / \mathrm{sec}$ at $60 \mathrm{~dB}$ SPL (A). Note that, whereas the short stimuli were separated from each other by 880 (syllable-initial) or 850 (syllable-final) $\mathrm{msec}$, and the long stimuli by $680(650) \mathrm{msec}$, the relevant cues in each case were separated by a constant 1 -sec interval.
For training stimuli, two transition durations of 30 and $100 \mathrm{msec}$ were presented, because our written identification data, obtained first, indicated that humans tended to hear stimuli with 10 - and 20 msec transitions as simply /a/. If a 30 -msec stimulus was presented, the subject was rewarded with a food pellet (monkeys) or feeder click (humans) for holding (no-go response) through the 2sec response interval, which was followed by a 4-sec (monkeys) or 1-sec (humans) intertrial interval (ITI). The 4-sec ITI allowed monkeys time to chew the pellet. Conversely, the subject was punished with an 8-sec timeout, during which time the light extinguished and the subject could not begin additional trials, for releasing to the 30 msec stimulus. If a $100-$ msec stimulus was presented, the subject was rewarded for releasing the disk (go response) during the 2-sec response interval, but was punished with an 8 -sec timeout for holding through it.

A correction procedure was in effect such that, after errors, the same training stimulus was presented on successive triais until a correct response occurred. Correction procedure trials were not counted in the data analysis; they were simply intended to prevent the development of response biases toward either the go or the nogo response.

For the initial training, only two stimuli were presented. Humans were verbally instructed to hold the disk if the stimulus sounded like $/ \mathrm{ba} /(/ \mathrm{bab} /)$, and to release if the stimulus sounded like/wa $/(/ \mathrm{baw} /)$. 
(a) JMS

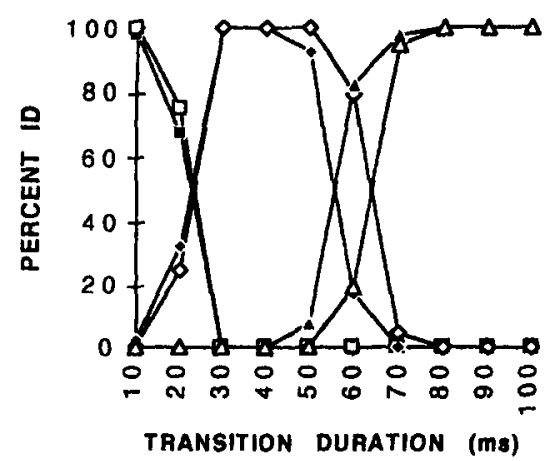

(c) KWM

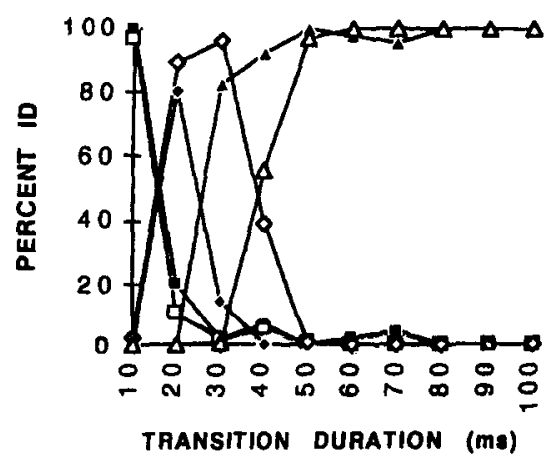

(b) JEM

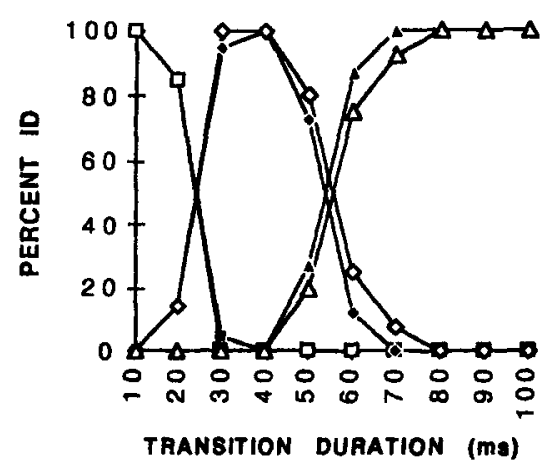

(d) DMB

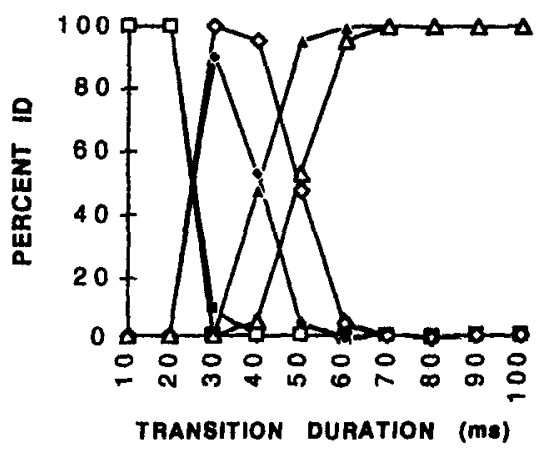

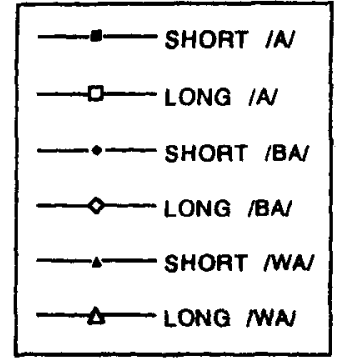

(ms)

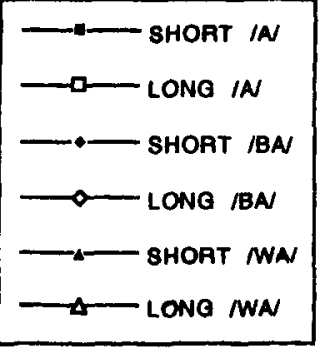

Figure 2. Written identification data for 4 human subjects for the syllable-initial condition. Percentages of $/ \mathrm{a} /$, $/ \mathrm{ba} /$, and $/ \mathrm{wa} / \mathrm{re}-$ sponses are plotted as a function of initial transition duration in milliseconds for the short and long syllable series.

Humans performed with nearly $100 \%$ accuracy right from the start of training. Monkeys were "instructed" to hold for $/ \mathrm{ba} /(/ \mathrm{bab} /)$ and release for $/$ wa $/($ baw $/)$ as follows: initially the no-go stimulus $/ \mathrm{ba} /(/ \mathrm{bab} /)$ was presented at a reduced intensity level in comparison with that of the go stimulus / wa /(/baw $/)$. This intensity difference was gradually reduced as training progressed. It required monkeys about 2 weeks to learn the basic procedure and respond to both stimulus categories with $>90 \%$ accuracy.

The stimuli were presented in daily sessions that alternated between the short and the long series. The test stimuli consisted of transition durations of $40,50,60,70,80$, and $90 \mathrm{msec}$. All subjects were rewarded for any response, hold or release, when these test stimuli were presented. The subjects passed through three training stages in which the percentage of training and test trials differed. Stage 1 consisted of $75 \%$ training trials but only $25 \%$ test trials; Stage 2 consisted of $62.5 \%$ training trials and $37.5 \%$ test trials; Stage 3, the final stage, consisted of $50 \%$ training trials and $50 \%$ test trials. To move to a higher stage, a subject had to perform for 5 successive days with greater than $90 \%$ correct responses to the training stimuli. After reaching Stage 3, the humans were tested for 5 sessions, each consisting of 65 rewards, and the monkeys were tested for 10 sessions, each consisting of 140 rewards. The data from sessions in which the training stimuli had more than $10 \%$ error rates were eliminated; we considered such error rates as an indication that the subjects were not operating under acceptable levels of stimulus control. Approximately $5 \%$ of the sessions (largely monkey data) were eliminated because of high error rates, and these occurred primarily in the early stages of training. Stage 3 data were used in the final analysis and were based on a total of 80 trials per stimulus for the humans and 160 for the monkeys.

\section{RESULTS}

\section{Experiment 1: Syllable-Initial Data}

Written identification by humans. The subjects in this experiment were J.M.S., D.M.B., J.E.M., and K.W.M. Figure 2 shows individual human functions for the short and long syllable series plotted together. Since the functions were all highly monotonic, boundaries between $/ \mathrm{a} /-/ \mathrm{ba} /-/ \mathrm{wa} /$ were calculated from the linearly interpolated transition durations at which a stimulus was identified $50 \%$ of the time as one syllable or anotherthat is, the points along the $x$-axis where the identification functions crossed each other. Boundaries for $/ \mathrm{a} / \mathrm{-} / \mathrm{ba} /$ were between 15 and $25 \mathrm{msec}$ and did not shift from the short to the long series. Boundaries for $/ \mathrm{ba} /-/ \mathrm{wa} /$ were between 25 and $55 \mathrm{msec}$ for the short series, and between 38 and $64 \mathrm{msec}$ for the long series. The / ba / $/$ wa / boundary shifted by $2-13 \mathrm{msec}$ from the short to the long series in individual subjects. Table 1 lists individual and mean boundaries. The average shift from the short to long series was $8 \mathrm{msec}$. 
Table 1

Individual and Mean $/ \mathrm{a} / / \mathrm{ba} /$ and $/ \mathrm{ba} / / \mathrm{wa} /$ Boundaries (in Milliseconds) of 4 Human Subjects as Measured in the Written Identification Experiment

\begin{tabular}{|c|c|c|c|c|}
\hline Subject & $\frac{\text { Short }}{\text { /a/-/ba/ }}$ & $\frac{\text { Long }}{\mid \mathrm{a} /-\mathrm{ba} /}$ & $\frac{\text { Short }}{\text { /ba/-/wa/ }}$ & Long \\
\hline J.M.S. & 23 & 23 & 55 & 64 \\
\hline J.E.M. & 24 & 24 & 54 & 56 \\
\hline D.M.B. & 25 & 25 & 40 & 50 \\
\hline K.W.M. & 15 & 15 & 25 & 38 \\
\hline$M_{\text {human }}$ & 218 & 21.8 & 43.5 & 52.0 \\
\hline
\end{tabular}

Note that the stimuli with very short transitions of 10 and $20 \mathrm{msec}$ were identified largely as $/ \mathrm{a} /$, indicating that the transitions were inaudible to the subjects. There are two potential reasons for this. First, use of a $10-\mathrm{msec}$ rise time would lower the amplitude of a greater proportion of these shorter transitions in comparison with the longer transitions. Second, use of a 5-msec default value for the synthesis frame rate would result in fewer sampling points for the shorter transitions in comparison with the longer ones. Thus, the transition information in the shorter transitions was probably impoverished relative to that in the longer transitions. For this reason, the 10 - and $20-\mathrm{msec}$ transitions were eliminated from the stop-glide continua in the experiments which compared humans and monkeys (see below).

Go/no-go identification by humans and monkeys. Subjects in this experiment were J.M.S., B.S.R., I.C.L., T.L.A., and W.A.S. (recall that I.C.L. and W.A.S. were non-native speakers of English) and the 4 monkeys. For each session, a hold response was classified as a / ba / response and a release response was classified as a /wa/ response. A psychometric function was obtained by plotting the percentage of $/ \mathrm{wd} /$ responses to the test stimuli as a function of transition duration. The identified boundary was considered to be the level of detection on the function half-way between the false alarm rate (i.e., / wa/ responses to the 30 -msec transition stimulus) and $100 \%$. For example, a $0 \%$ false alarm rate would result in a boundary at exactly the $50 \%$ level of detection, but a $10 \%$ false alarm rate would result in a boundary at the $55 \%$ level.

Figure 3 shows representative identification functions for the short and the long syllable series plotted together. Figures $3 a-3 b$ show two human functions; Figures $3 c-3 d$ show two monkey functions. Individual and averaged boundaries are listed in Table 2. Human subjects had /ba/-/wa/boundaries between 39 and $54 \mathrm{msec}$ for the short series and between 45 and $65 \mathrm{msec}$ for the long series. The boundaries of the two non-native speakers of English were similar to those of the English-speaking subjects. Monkeys had boundaries ranging between 47 and $52 \mathrm{msec}$ for the short series and 53 and $59 \mathrm{msec}$ for the long series. The mean boundary was at 46 and $52 \mathrm{msec}$ for humans, and at 50 and $56 \mathrm{msec}$ for monkeys; thus the boundary shifted by about $6 \mathrm{msec}$ for both humans and monkeys.
These data were analyzed by using a two-factor analysis of variance (ANOVA) to examine the effects of species and series. The species effect was not significant $[F(1,7)=$ $1.99, p>.05]$, indicating that human and monkey boundaries were at similar locations along the continuum. The main effect of series was significant $[F(1,7)=$ $139.55, p<.01]$, verifying that the boundary changed between the short and long series. The interaction was not significant $[F(1,7)=.40, p>.05]$, indicating that the magnitudes of the boundary changes were similar for humans and monkeys.

The present data show that both human and monkey mean phoneme boundaries were at similar locations along the syllable-initial stop-glide continuum, and boundaries shifted in a similar manner from the short to the long series. Also, the mean human boundaries from both the written and the go/no-go identification procedures were highly similar and within $2 \mathrm{msec}$ of each other.

The inclusion of the two non-native speakers of English, I.C.L. and W.A.S., did not appear to influence the range or variability of human boundaries obtained. Their boundary locations were well within the ranges of the native English listeners. The shortest short-series /ba/ / wa / boundary $(25 \mathrm{msec})$ was obtained by native English listener K.W.M. in the written identification procedure, the longest $(55 \mathrm{msec})$ by native English listener J.M.S. in the same procedure. The shortest long-series boundary ( $38 \mathrm{msec})$ was again obtained by K.W.M. in the written identification procedure, and the longest $(65 \mathrm{msec})$ by J.M.S. in the go/no-go identification procedure. Also, the subject who showed the least amount of shift effect $(2 \mathrm{msec})$ was a native English listener (J.E.M.) in the written identification procedure, and the one who showed the greatest amount of shift $(13 \mathrm{msec})$ was native English listener K.W.M. in the written identification procedure.

\section{Experiment 2: Syllable-Final Data}

Written identification by humans. The subjects in this experiment were J.M.S., J.E.M., K.W.M., and R.A.K. Individual data from the written procedure are shown in Figure 4. J.M.S. and J.E.M. showed the most orderly data, with boundary shifts for both /ba/-/bab/and /bab/ /baw/moving toward longer transition durations from the short to the long series. K.W.M. and R.A.K. showed less orderly data. Neither could accurately differentiate between / ba/and / bab/in the short series, although they could in the long series. Table 3 lists boundaries for the 4 humans. The average shift from the short to the long series was $8 \mathrm{msec}$.

As with the syllable-initial data discussed above, subjects were unable to detect the 10- and 20-msec transitions, and so these stimuli were eliminated from the continuum in the following experiment conducted with monkeys.

Go/no-go identification by humans and monkeys. The subjects were J.M.S., I.C.L., K.W.M., T.L.A., and the 4 monkeys. Results from two representative humans 
(a) HUMAN TLA

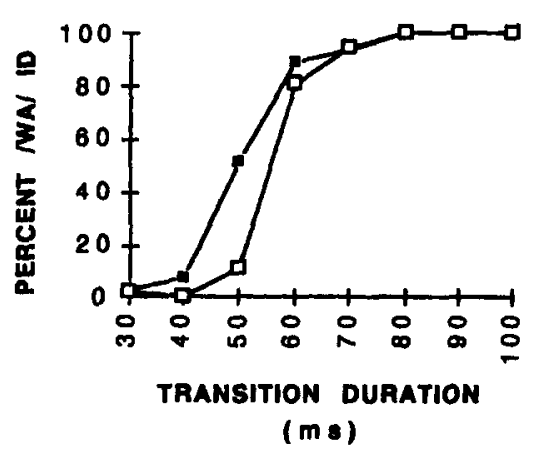

(c) MONKEY DART

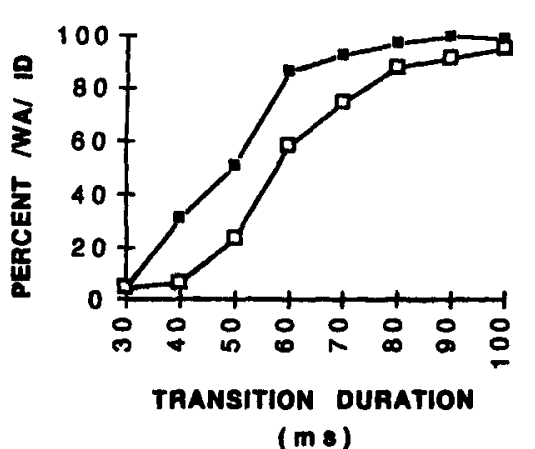

(b) HUMAN ICL

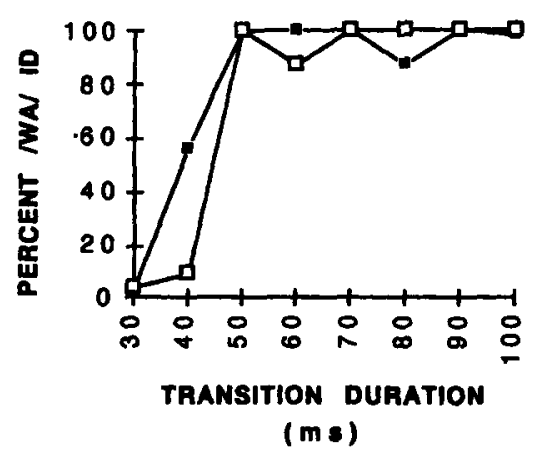

(d) MONKEY ANDY

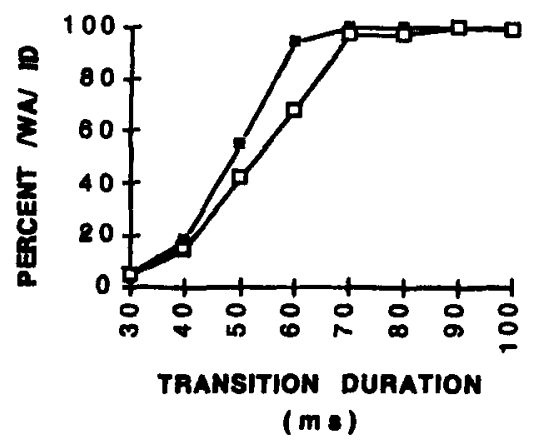

Figure 3. Individual go/no-go identification data for 2 human (a,b) and 2 monkey (c,d) subjects for the syllableinitial condition. Percent / wa / identification is plotted as a function of transition duration in milliseconds.

are shown in Figures 5a-5b, and from 2 monkeys, in Figures $5 \mathrm{c}-5 \mathrm{~d}$. Mean boundaries are shown in Table 4 . The humans show about a 7-msec shift from the short (45.4$\mathrm{msec})$ to the long $(51.8-\mathrm{msec})$ series, indicating that more / bab/sounds were identified in the longer continuum. Monkeys showed a shift of about $10 \mathrm{msec}$ from the short (51.2-msec) to the long $(60.5-\mathrm{msec})$ series. Mean monkey boundaries occurred at longer transition durations than did human boundaries.

Boundary locations were analyzed with a two-factor ANOVA. Both main effects were significant: species $[F(1,7)=10.7, p<.05]$, indicating that monkey boundaries were at longer transition durations than humans', and series $[F(1,7)=72.05, p<.01]$, indicating that the overall boundaries shifted from the short to the long series. The interaction was not significant $[F(1,7)=2.39, p>.05]$, indicating that the boundary changes were of similar magnitude in humans and monkeys.

The present data show that both humans and monkeys perceived shifting syllable-final boundaries along stopglide continua with changes in overall syllable duration, but that the monkey boundaries were at significantly longer durations than those for the human boundaries. Again, among the human subjects, Spanish subject I.C.L. exhibited syllable-final boundaries within the range of those for the native English listeners.
In Figure 6, all the present data from humans and monkeys from all experimental conditions are compared. For humans, the syllable-initial series, the syllable-final series, and the written and the go/no-go identification procedures all resulted in similar mean boundaries within a range of about $4 \mathrm{msec}$. Monkey boundaries for both series durations occurred within a 4-msec range and appeared at longer durations than humans'. Recall, however, that our statistical analyses indicated that monkey boundaries were

Table 2

Individual and Mean / ba $/ /$ wa / Boundaries (in Milliseconds) of 5 Humans and 4 Monkeys as Measured in the Go/No-Go Identification Experiment

\begin{tabular}{lcc}
\hline & Short & Long \\
Subject & /ba/-/wa & /ba $/ /$ wa $/$ \\
\hline J.M.S. & 54 & 65 \\
T.L.W. & 50 & 56 \\
B.S.R. & 43 & 48 \\
I.C.L. & 39 & 45 \\
W.A.S. & 44 & 48 \\
$M_{\text {human }}$ & 46.0 & 52.4 \\
Andy & 49 & 54 \\
Dart & 51 & 59 \\
Harry & 52 & 56 \\
Port & 47 & 53 \\
$M_{\text {monkey }}$ & 49.8 & 55.5 \\
\hline
\end{tabular}


Table 3

Individual and Mean / ba / / bab/and / bab//baw/ Boundaries (in Milliseconds) of 4 Human Subjects as Measured in the Written Identification Experiment

\begin{tabular}{|c|c|c|c|c|}
\hline & Short & Long & Short & Long \\
\hline Subject & $/ \mathrm{ba} /-/ \mathrm{bab} /$ & $/ \mathrm{ba} /-/ \mathrm{bab} /$ & $/ \mathrm{bab} /-/ \mathrm{baw} /$ & $/ \mathrm{bab} /-/ \mathrm{baw} /$ \\
\hline J.M.S. & 15 & 23 & 46 & 55 \\
\hline J.E.M. & 15 & 19 & 42 & 53 \\
\hline R.A.K. & * & 25 & 44 & 45 \\
\hline K.W.M. & * & 25 & 39 & 52 \\
\hline$M_{\text {human }}$ & 15.0 & 23.0 & 42.8 & 51.3 \\
\hline
\end{tabular}

*Boundary could not be determined, owing to a nonmonotonic function.

similar to those of humans for syllable-initial data, but at significantly longer durations for the syllable-final data.

\section{DISCUSSION}

\section{Comparison With Other Stop-Glide Data}

Figure 7 shows the present mean syllable-initial / ba//wa/ boundaries from both the written and the go/no-go identification experiments plotted in comparison with previously reported human stop-glide syllable-initial boundaries. The absolute locations of the boundaries vary: For example, for long syllables of about 300-msec dura- tion, the shortest boundaries of $35-40 \mathrm{msec}$ occur in Pisoni et al. (1983) and Diehl and Walsh (1989), whereas the longest boundaries of 53-55 msec occur in Godfrey and Millay (1981) and in the present study. Miller and Liberman's (1979) boundary of about $47 \mathrm{msec}$ falls in between the others.

Some of this variability may be related to the range of transition durations used in the stimulus sets. In both the present study and that of Godfrey and Millay (1981), transition durations ranged up to $100 \mathrm{msec}$ or more; in the other studies, durations ranged up to only $64 \mathrm{msec}$. Thus, a stimulus set consisting of longer transitions may result in boundaries at relatively longer transition durations. Other researchers have also reported range effects in human speech perception (e.g., Brady \& Darwin, 1978). Despite these differences in stimulus ranges between the various studies, however, all the data in Figure 7 show boundary shifts toward longer durations as syllable duration increases.

\section{The Stop-Glide Context Effect and Weber's Law}

One possible psychoacoustic mechanism underlying the stop-glide boundary shift effect might be Weber's law, operating in the time domain within the context of a complex sound. For example, just as the threshold for a (a) JMS

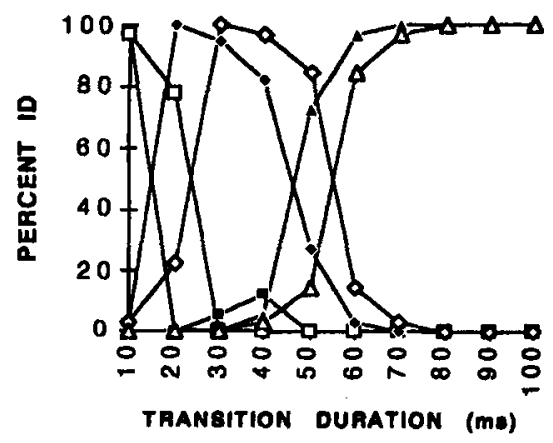

(c) KWM

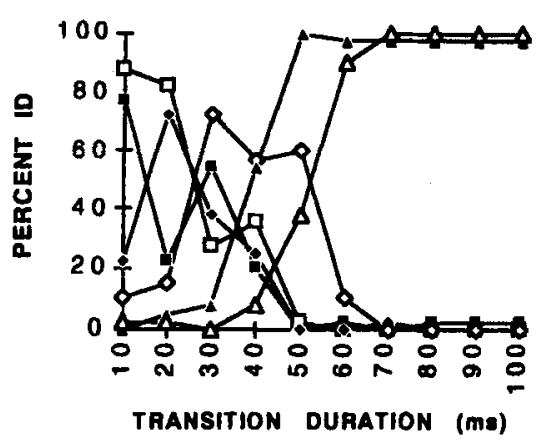

(b) JEM

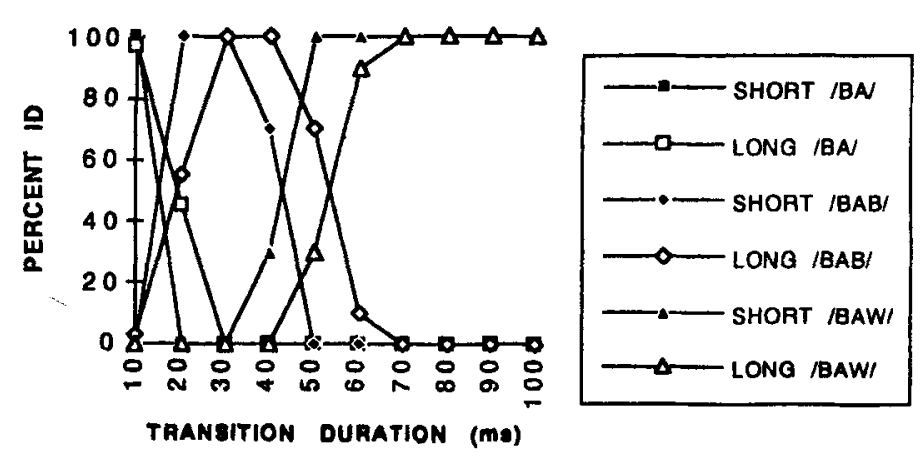

(d) RAK

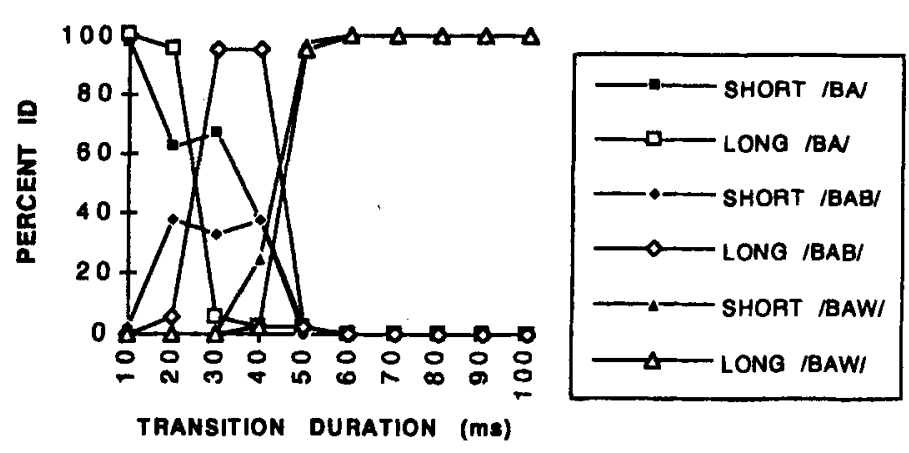

Figure 4. Written identification data for 4 human subjects in the syllable-final condition. Percentages of $/ \mathrm{ba} /, / \mathrm{bab} /$, and $/ \mathrm{baw} / \mathrm{re}-$ sponses are plotted as a function of final transition duration in milliseconds for the short and long syllable series. 
(a) HUMAN TLA

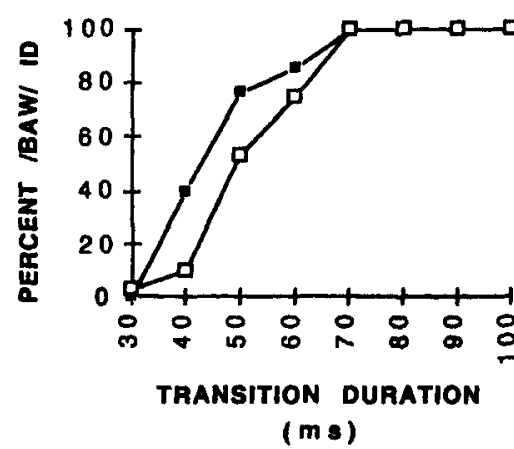

(c) MONKEY DART

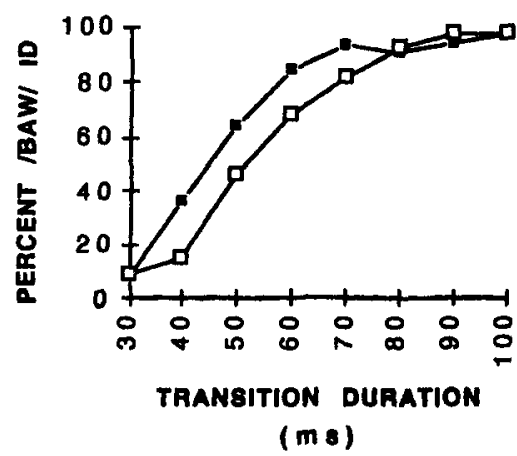

(b) HUMAN ICL

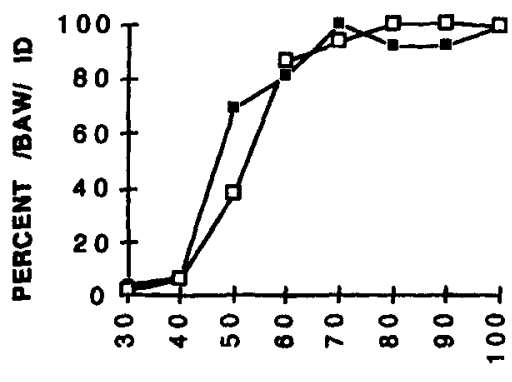

TRANSITION DURATION $(\mathrm{m} s)$

(d) MONKEY ANDY

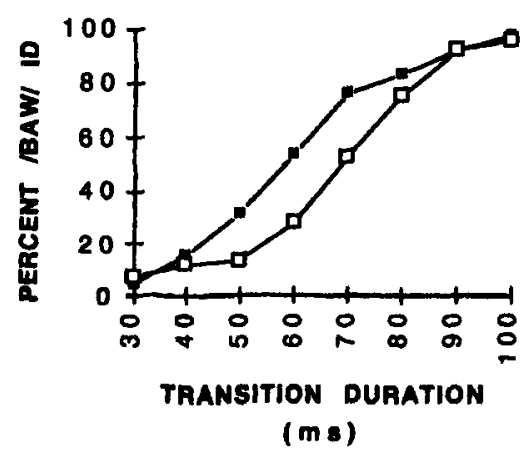

Figure 5. Individual go/no-go identification data for 2 human (a,b) and 2 monkey (c,d) subjects for syllable-final data. Percent / baw / identification is plotted as a function of transition duration in milliseconds.

change in simple tone duration increases as an almost constant proportion as the standard duration of the tone increases, the threshold for detecting a change from $/ b /$ to $/ \mathrm{w} /$ also increases as the standard syllable duration increases. Listeners do not process the transition apart from the total syllable context, and when the transition duration surpasses a certain proportion of the syllable duration, its percept changes from a stop to a glide.

Since the present tasks involve processing the change in duration of a frequency transition, it is of interest to compare our obtained boundaries with actual psychoacoustic measures of duration discrimination. We have measured pure tone duration DLs in both humans and monkeys (Sinnott, Owren, \& Petersen, 1987). Human and monkey duration DLs measured over a range of 100 $400 \mathrm{msec}$ are shown in Figure 8, plotted on a log scale to equate proportional increases in the DLs. Also shown are the present human and monkey stop-glide boundary shifts.

These data suggest three striking aspects: First, the stop-glide boundaries for humans and monkeys are quantitatively much more similar than their pure tone duration DLs. The monkey pure tone duration DLs are about twice those of humans: For a $100-\mathrm{msec}$ tone, the monkey DL is $31 \mathrm{msec}$, but the human DL is $16 \mathrm{msec}$. If perception of the stop-glide boundary shift were based on Weber's law, we would expect that monkeys would show the shift effect as humans do, but that their boundaries would occur at transition durations twice as long as those of humans. Clearly, this is not the case, because human and monkey boundaries for a $150-\mathrm{msec}$ syllable are at 46 and $50 \mathrm{msec}$, respectively.

Second, for both species, the slope of the boundary shift function is much flatter than that of the pure tone duration DL, indicating that a given change in the sylla-

Table 4

Individual and Mean / bab/-/baw / Boundaries (in Milliseconds) of 5 Humans and 4 Monkeys as Measured in the Go/No-Go Identification Experiment

\begin{tabular}{lcc} 
& $\begin{array}{c}\text { Short } \\
\text { Subject }\end{array}$ & $\frac{\text { Long }}{\text { /bab/-/baw/ } / \text { bab } / \text { baw } /}$ \\
\hline J.M.S. & 51 & 59 \\
T.L.W. & 45 & 49 \\
B.S.R. & 43 & 48 \\
K.W.M. & 42 & 51 \\
I.C.L. & 46 & 52 \\
$M_{\text {human }}$ & 45.4 & 51.8 \\
Andy & 60 & 70 \\
Dart & 47 & 54 \\
Harry & 53 & 56 \\
Port & 45 & 62 \\
$M_{\text {monkey }}$ & 51.3 & 60.5 \\
\hline
\end{tabular}




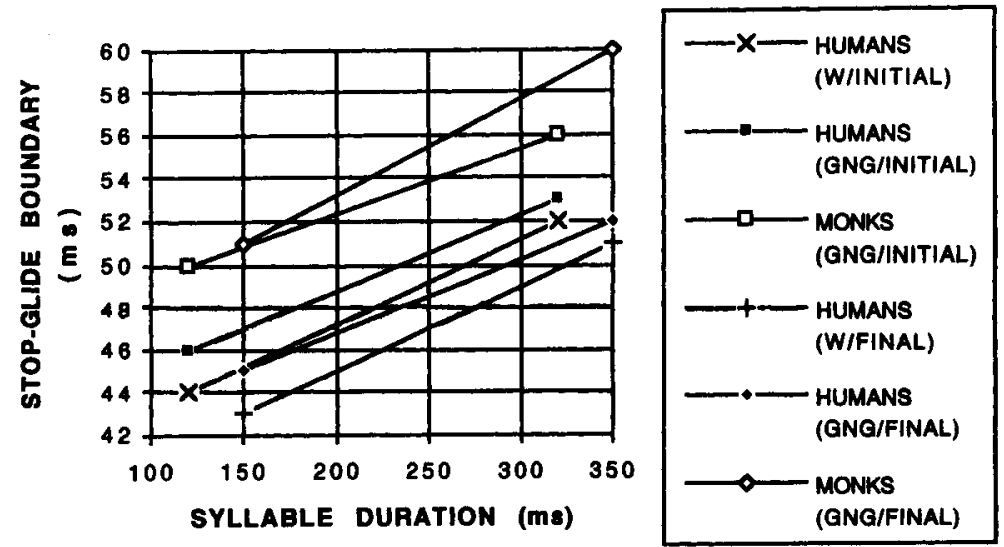

Figure 6. Comparison of all human and monkey identification data obtained in the present series of experiments. W, written identification procedure; GNG, go/no-go identification procedure.

ble or standard duration changes the location of the phoneme boundary much less than it changes the duration DL.

Third, for humans, the duration DL is much more acute than that which is needed for one to identify a boundary shift. For monkeys, on the other hand, overlap occurs in the two functions, indicating that there might be some relation between the two temporal discrimination tasks.

In sum, Figure 8 shows that there is no straightforward relationship between the pure tone duration $\mathrm{DL}$ and the stop-glide boundary shift. This observation weakens the hypothesis that basic temporal discrimination abilities underlie the shift effect.

Interestingly, monkeys seem to provide much better models for the human stop-glide shift effect than they do for simple pure tone duration discrimination. Two possible reasons for this are that (1) the human-monkey correspondence in the shift effect is purely coincidental; and (2) the human shift effect is an evolutionarily very old behavior, appropriating mechanisms already available in a common primate ancestor of both man and monkey. In contrast, the human pure tone duration DL appears to have evolved later, after humans diverged from monkeys and is more specialized in humans and twice as sensitive as that of monkeys.

Lest it be thought that the pure tone duration DL might be totally irrelevant to the study of any acoustic communication system, it should be noted that we have found a very accurate relationship between the duration $\mathrm{DL}$ and the ability of humans and monkeys to discriminate temporal differences in peak position onset along a Japanese macaque coo call continuum (Hopp, Sinnott, Owren, \& Petersen, 1992). These results indicate that some animal communication systems may have a relatively simple
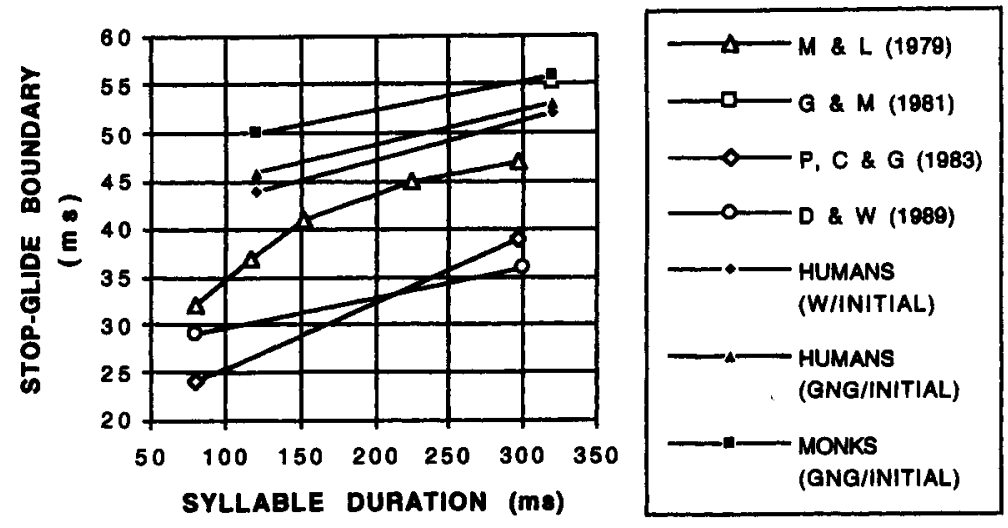

Figure 7. Identified stop-glide phoneme boundaries as a function of syllable duration for the present study compared with those obtained in previous syllableinitial human studies. M\&L, Miller \& Liberman (1979); G\&M, Godfrey \& Millay (1981); P, C, \& G, Pisoni, Carrell, \& Gans (1983); D\&W, Diehl \& Walsh (1989). $G \& M$ actually used syllable durations ranging from 320 to $430 \mathrm{msec}$; here they are plotted as 320-msec durations. 


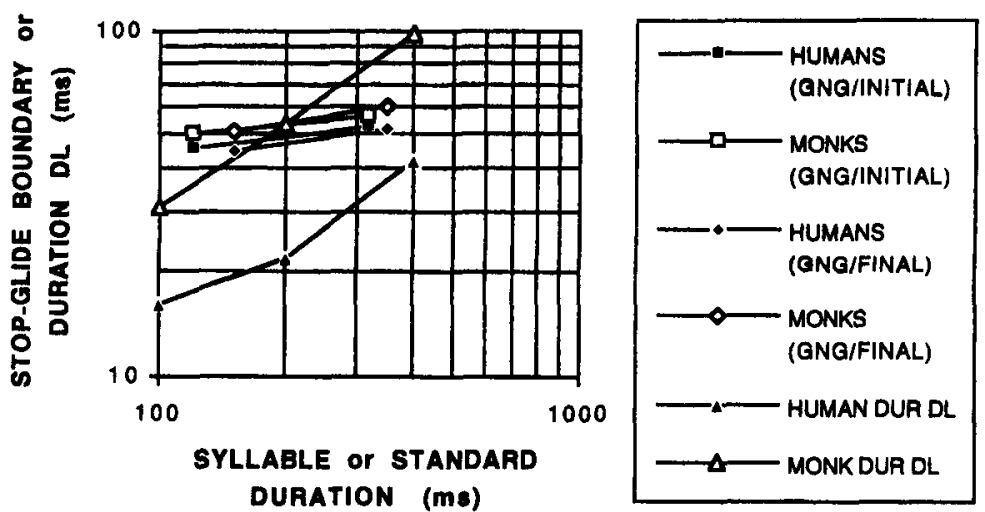

Figure 8. The present stop-glide boundaries for humans and monkeys compared with the species' pure tone duration DLs as measured in Sinnott et al. (1987).

pyschoacoustic basis that is based on the pure tone duration DL, but that obviously is not the case for the stopglide boundary shift effect.

\section{The Stop-Glide Context Effect and "Durational Contrast"}

Diehl and Walsh (1989) have proposed a "durational contrast" hypothesis in their attempt to explain the stopglide boundary shift. According to this hypothesis, the perceived length of a given acoustic segment is affected contrastively by the duration of adjacent segments. Thus an ambiguous interval (e.g., a 40-msec transition) will be heard as shorter $(/ \mathrm{b} /)$ in the context of a long segment (300-msec vowel) and as longer $(/ \mathrm{w} /$ ) in the context of a short segment (100-msec vowel). However, this hypothesis has some obvious shortcomings. First, it does little more than describe the data qualitatively. Second, it provides no quantitative account of the shift effect and cannot predict how much of an effect will occur with a specified change in segment duration. Third, Fowler (1990) has criticized the hypothesis by demonstrating some auditory experiments in which the results come out exactly opposite to those predicted by the hypothesis.

\section{The Stop-Glide Context Effect and Temporal Masking}

Another possibility is that the stop-glide context effect is due to some type of temporal masking of the formant transitions by the associated vowel; a longer vowel results in more masking than does a shorter vowel, masking part of the transition and causing the percept of ambiguous transitions to change from glides to stops. If so, the syllable-initial effect might be due to backward masking, whereas the syllable-final effect might be due to forward masking. However, some of our own data in the syllable-final condition would argue against this hypothesis, since some of our subjects actually found it harder to identify the very short transitions in the context of the shorter vowel (see Figures 4c-4d).

The syllable-final data are of particular interest to us because the monkey stop-glide boundaries in this condi- tion were at longer transition durations than humans'. To the best of our knowledge, however, there are no psychoacoustic data from monkeys that would support a hypothesis that monkeys are more adversely affected by forward masking than are humans. For example, Serafin, Moody, and Stebbins (1982) examined forward masking tuning curves in monkeys and concluded that they were similar to previously reported human data.

\section{Differences Between Syllable-Initial and Syllable-Final Context Effects}

Let us return to our observation that the monkey boundaries were at significantly longer transition durations than humans' for the syllable-final series. As discussed above, we are not aware of any human-monkey comparative psychoacoustic data that would support this observation. Although all subjects were tested on the syllable-final contrasts after the syllable-initial contrasts, we can offer no reason why this ordering of the testing conditions would cause differential effects in humans and monkeys.

One important aspect of the syllable-final condition, however, might account for human and monkey differences: the presence of the appended $30-\mathrm{msec} / \mathrm{b} /$ consonant at the beginning of the syllable. As Miller and Liberman (1979) have shown, when additional consonants are appended to the syllable being tested for the stop-glide shift effect, human listeners respond as if the appended consonant were not part of the overall syllable duration, and their phoneme boundaries actually shift to shorter transition durations. Therefore, whereas humans may have evaluated the final stop-glide boundary relative to the duration of the vowel alone (e.g., 120 or $320 \mathrm{msec}$ ), monkeys may have evaluated it relative to the entire syllable duration (e.g., 150 or $350 \mathrm{msec}$ ).

If so, the difference observed between humans and monkeys may not have been due to syllable-final position per se, but to a difference in how the structure of the syllable was perceived-that is, in what portion of the syllable was considered the standard. If humans were using a 120 - or a 320 -msec standard, whereas monkeys were using a $150-$ or a 350 -msec standard, this might account 
for the monkey boundaries' being at longer absolute durations than humans' in the syllable-final condition. Thus there could well be a difference in how humans and monkeys would compensate for speech rate in complex CVC syllables: For humans, replacing a portion of the vowel with a transition would indicate a faster speaking rate, but for monkeys, this would not.

\section{The Logic of Human-Animal \\ Comparisons in Speech Perception}

The logic of human-animal comparative experiments is as follows:

1. Similarity in identification performance argues against a claim that speech perception requires neural structures unique to humans. If humans and animals show similar behavior patterns in responding to speech, it follows that a specialized mechanism is not required in order to explain human behavior patterns. As discussed in the introduction to this paper, gross similarities between humans and animals for categorical perception, phonetic category formation, trading relations, and perceptual constancy suggest that these effects may not require a specialized speech mechanism. To these phenomena we tentatively add the stop-glide context effect.

2. Assuming that a specialized speech mechanism is not necessary for particular patterns of speech perception, it might also be maintained that similarity in human and animal performance can be attributed to common auditory mechanisms. We must also consider the possibility, however, that although humans and animals may show gross similarities in speech perception, as discussed in (1) above, the underlying mechanisms might still be different and might come to light as more precise experiments are devised. The present data for the stop-glide context effect might be indicative of such a case: Both humans and monkeys showed a similar effect in syllableinitial position, but the results of appending a consonant appear to have elicited different perceptual mechanisms in syllable-final position, with humans constructing a stop-glide boundary based on the duration of the vowel, and monkeys doing so based on the duration of the entire syllable. Data such as these might eventually indicate that humans do, in fact, compensate for speech rate in a very precise way that is unavailable to monkeys, at least as the structure of the syllable changes and becomes more complex. Further controlled research will be necessary for this question to be answered.

\section{REFERENCES}

BRADY, S. A., \& DaRWIN, C. J. (1978). Range effect in the perception of voicing. Journal of the Acoustical Society of America, 63, 1556-1558.

Burdick, C., \& Miller, J. D. (1975). Speech perception by the chinchilla: Discrimination of sustained /a/ and /i/. Journal of the Acoustical Society of America, 58, 415-427.

Dent, M. L., Powell, E. F., Pierce, A., \& Dooling, R. J. (1995). Discrimination of synthetic/ba-wa / by budgerigars (Melopsittacus undulatus). Journal of the Acoustical Society of America, 97 (5, Pt. 2), 3417. DIEHL, R. L., \& WALSH, M. A. (1989). An auditory basis for the stimulus- length effect in the perception of stops and glides. Journal of the Acoustical Society of America, 85, 2154-2164.

Dooling, R. J., BesT, C. T., \& BRown, S. D. (1995). Discrimination of synthetic full-formant and sinewave/ra-la/ continua by budgerigars (Melopsittacus undulatus) and zebra finches (Taeniopygia guttata). Journal of the Acoustical Society of America, 97, 1839-1846.

Dooling, R. J., \& BRown, S. D. (1990). Speech perception by budgerigars (Melopsittacus undulatus): Spoken vowels. Perception \& Psychophysics, 47, 568-574.

Dooling, R. J., OKanoya, K., \& Brown, S. D. (1989). Speech perception by budgerigars (Melopsittacus undulatus): The voiced-voiceless distinction. Perception \& Psychophysics, 46, 65-71.

Eimas, P., \& Miller, J. (1980). Contextual effects in infant speech perception. Science, 209, 1140-1141.

FowLER, C. A. (1990). Sound-producing sources as objects of perception: Rate normalization and nonspeech perception. Journal of the Acoustical Society of America, 88, 1236-1249.

GODFREY, J., \& MiLlAY, K. (1981). Discrimination of the "tempo of frequency change" cue. Journal of the Acoustical Society of America, 69, 1446-1448.

Hopp, S., Sinnott, J., Owren, M., \& Petersen, M. (1992). Differential sensitivity of Japanese macaques and humans to peak position along a synthetic coo call continuum. Journal of Comparative Psychology, 106, 128-136.

Jusczyk, P., Pisoni, D., Reed, M., Fernald, A., \& Myers, M. (1983). Infants' discrimination of the duration of a rapid spectrum change in nonspeech signals. Science, 222, 175-177.

KLUENDER, K. R. (1991). Effects of first formant onset properties on voicing judgments result from processes not specific to humans. Journal of the Acoustical Society of America, 90, 83-96.

KLuender, K. R., DieHL, R. L., \& KilleEN, P. R. (1987, September). Japanese quail can leam phonetic categories. Science, 237, 1195-1197.

KLUENDER, K. R., \& LotTo, A. J. (1994). Effects of first formant onset properties on [-voice] judgments result from auditory processes not specific to humans. Journal of the Acoustical Society of America, 95, 1044-1052.

KoJima, S., \& Kiritani, S. (1989). Vocal-auditory functions in the chimpanzee: Vowel perception. International Journal of Primatology, 10, 199-213.

KUHL, P. K. (1981). Discrimination of speech by nonhuman animals: Basic auditory sensitivities conducive to the perception of speechsound categories. Journal of the Acoustical Society of America, 70, 340-348.

KuHL, P. K. (1991). Human adults and human infants show a "perceptual magnet effect" for the prototypes of speech categories, monkeys do not. Perception \& Psychophysics, 50, 93-107.

KUHL, P. K., \& MiLlER, J. D. (1978). Speech perception by the chinchilla: Identification functions for synthetic VOT stimuli. Journal of the Acoustical Society of America, 63, 905-917.

KUHL, P. K., \& PADDEN, D. M. (1982). Enhanced discriminability at the phonetic boundaries for the voicing feature in macaques. Perception \& Psychophysics, 32, 542-550.

KuHL, P. K., \& PADDEN, D. M. (1983), Enhanced discriminability at the phonetic boundaries for the place feature in macaques. Journal of the Acoustical Society of America, 73, 1003-1010.

MiLLER, J. L., \& LiBERMAN, A. (1979). Some effects of later-occurring information on the perception of stop consonant and semivowel. Perception \& Psychophysics, 25, 457-465.

NitTrouer, S., \& Studdert-KenNedy, M. (1986). The stop-glide distinction: Acoustic analysis and perceptual effect of variation in syllable amplitude envelope for initial /b/and /w/. Journal of the Acoustical Society of America, 80, 1026-1029.

Pisoni, D. B., Carrell, T. D., \& Gans, S. J. (1983). Perception of the duration of rapid spectrum changes in speech and nonspeech signals. Perception \& Psychophysics, 34, 314-322.

Serafin, J., Moody, D., \& Stebrins, W. (1982). Frequency selectivity of the monkey's auditory system; Psychophysical tuning curves. Journal of the Acoustical Society of America, 71, 1513-1518.

SinNoTt, J. M. (1994). Comparisons of human and monkey differential sensitivity to speech, non-speech and monkey speech sounds. In 
J. Menon (Ed.), Current topics in acoustic research (pp. 355-364). Trivandrum, India: Council for Scientific Research.

Sinnott, J, M., \& Brown, C. H. (1997). Perception of the English liquid / ra-la/ contrast by humans and monkeys. Journal of the Acoust $i$ cal Society of America, 102, 588-602.

Sinnott, J. M., Brown, C. H., Malik, W. T., \& Kressley, R. A. (1997). A multidimensional scaling analysis of vowel discrimination in humans and monkeys. Perception \& Psychophysics, 59, 1214-1224.

Sinnott, J. M., Owren, M., \& Petersen, M. (1987). Auditory duration discrimination in Old World monkeys and humans. Journal of the Acoustical Society of America, 82, 465-470.
Stevens, E. B., Kuhl, P. K., \& Padden, D. M. (1988), Macaques show context effects in speech perception. Journal of the Acoustical Society of America, 84 (Suppl. 1), S77-S78.

WATERS, R. S., \& WILSON, W. A., JR. (1976). Speech perception by rhesus monkeys: The voicing distinction in synthesized labial and velar stop consonants. Perception \& Psychophysics, 19, 285-289.

(Manuscript received December 17, 1996; revision accepted for publication September 14, 1997.) 